\title{
$\mathrm{MBT}$ 활용 대인관계향상 프로그램이 직업군인의 자기수용, 자존감 및 타인수용에 미치는 효과
}

최송원 ${ }^{1} \cdot$ 김희숙 ${ }^{2}$

구미정신건강복지센터 정신전문간호사 ${ }^{1}$, 경북대학교 간호대학 - 간호과학연구소 교수 ${ }^{2}$

\section{Effects of an Interpersonal Relationship Improvement Program using MBTI on Self-acceptance, Self-esteem, and Acceptance of others of Professional Soldiers}

\author{
Choi, Song Won ${ }^{1} \cdot$ Kim, Hee Sook ${ }^{2}$ \\ ${ }^{1}$ Psychiatric Mental Health Nurse Practitioner, Gumi Mental Health Care Cental, Gumi \\ ${ }^{2}$ Professor, College of Nursing · The Research Institute of Nursing Science, Kyungpook National University, Daegu, Korea
}

\begin{abstract}
Purpose: The purpose of this study was to investigate effects of an interpersonal relationship improvement program using MBTI on self-acceptance, self-esteem and acceptance of others of professional soldiers. Methods: The participants were 36 professional soldiers in G City, including an experimental group $(n=18)$ and a control group $(n=18)$. The research was carried out from June to July, 2015. The intervention was provided to the experimental group once a week over 8 weeks, for 90 minutes per session. Date were analyzed using $x^{2}$ test, t-test, Fisher's exact probability test, and ANCOVA with the SPSS/WIN 12.0 program. Results: Experimental group who took part in the interpersonal relationship improvement program using MBTI had higher self-acceptance score ( $F=26.39, p<.001)$, self-esteem score $(F=16.61, p<.001)$, and acceptance of others score $(F=0.47, p=.017)$ than the control group that did not participate. Conclusion: The results indicate that an interpersonal relationship improvement program using MBTI enhanced self-acceptance, self-esteem and acceptance of others of professional soldiers. Therefore, the interpersonal relationship improvement program using MBTI could be one of programs to improve self-acceptance, self-esteem and acceptance of others of professional soldiers.
\end{abstract}

Key Words: Relationship; Acceptance; Self esteem; Military personnel

\section{서 론}

1. 연구의 필요성

최근 들어 일반병사의 군무이탈, 구타, 자살사고 등의 군 부
적응이 심각한 사회문제로 대두되고 있으며[1], 군 부적응은 일반병사만의 문제는 아니며, 직업군인의 경우에도 어려움을 겪고 있다[2]. 직업군인의 $11.1 \%$ 는 불안, 우울, 충동성과 같은 심리적 문제로 전문가의 상담이나 진료가 필요하며[3], 그로 인해 부하직원이나 병사들에 대한 상습폭행을 보이거나[3] 자

주요어: 대인관계, 수용, 자존감, 군인

Corresponding author: Kim, Hee Sook https://orcid.org/0000-0002-8669-0166

College of Nursing, Kyungpook National University, 680 Gukchaebosang-ro, Jung-gu, Daegu 41944, Korea.

Tel: +82-53-420-4927, Fax: +82-53-422-4926, E-mail: hskim4114@nate.com

- This article is a condensed form of the first author's master's thesis from Kyungpook National University.

Received: Feb 7, 2020 | Revised: Mar 17, 2020 | Accepted: Mar 24, 2020

This is an open access article distributed under the terms of the Creative Commons Attribution Non-Commercial License (http://creativecommons.org/licenses/ by-nc/3.0), which permits unrestricted non-commercial use, distribution, and reproduction in any medium, provided the original work is properly cited. 
살이라는 극단적인 선택까지도 이어질 수 있다[4]. 이러한 직 업군인의 정신건강 문제는 군 조직이 일반사회 조직과는 다른 특수성을 가지고 있기 때문이다[2].

군 조직은 국가의 수호라는 이름 아래 목숨까지 담보로 한 책임감과 함께 강력한 구속성을 가진다[5]. 또한 군대는 조직 지향적이며, 통일주의와 희생을 요구하는 강제적인 측면이 강 하고 상명하복의 무조건적인 명령복종 체계가 다른 조직에 비 해 더 많다[5]. 이런 특성은 조직 내 단결과 응집력을 강화시키 기도 하지만 구성원들 간 의사소통을 방해하고 대인관계의 갈 등을 유발하여 우울, 무기력, 직무 스트레스와 같은 정신건강 문제를 발생시킬 수 있다[6]. 반면 엄격한 규율과 폐쇄적인 군 생활로 발생하는 심리적 부적응에 대해 상관과 동료들 간 친 밀하고 신뢰감 있는 대인관계 구축이 보호요인으로 보고되고 있다[7].

지금까지 알려진 직업군인의 정신건강을 위한 대처자원으 로는 자기효능감[8], 자아탄력성과 자존감[9], 자기수용 및 타 인수용[10] 등이 있으며, 이 중 자기수용, 자존감, 타인수용은 대인관계를 향상시키는 중요한 내적자원으로 볼 수 있다[11]. 자기수용은 자기개념과 유사한 것으로 자신을 이해하고 있는 그대로 받아들이는 것이며[12], 자존감은 자신을 수용하고 존 중하여 스스로를 가치 있는 존재라고 느끼는 것을 말한다[13]. 높은 자기수용과 자존감은 자신에 대해 긍정적인 생각과 삶의 태도를 가지게 하고 의사소통 능력을 향상시켜 대인관계에서 오는 심리적 압박감을 감소시킬 수 있다[14]. 또한 자기수용과 자존감은 상대방을 있는 그대로 받아들이고 긍정적으로 인식 하는 타인수용과 밀접한 연관이 있다고 볼 수 있다[15]. 타인수 용은 자존감의 구성개념으로[16] 타인수용이 높을수록상대방 을 객관적으로 지각하여 대인관계의 조화를 보이고 조직 내 상 호작용을 촉진시키는 중요한 역할을 한다[11].

MBTI (Myers-Brigs Type Indicator)는 Jung의 심리유형 론에 근거하여 Myers와 Briggs가 개발한 성격유형 검사 도구 이다[17]. MBTI는 과학적으로 입증된 도구로서 이를 프로그 램에 활용할 경우 성격유형에 따른 특성과 행동에 대한 이해를 객관적으로 돕고[18] 집단원들과의 상호교류를 통해 긍정적인 역동을 형성하는 것을 돕는다[19]. 또한 MBTI는 자신을 있는 그대로 수용하여 자존감을 높이고 스트레스 상황에 대하여 긍 정적으로 인식하도록 변화시키며[18] 효과적인 의사소통 기술 을 습득하도록 도와줌으로써 다른 사람과의 관계를 향상시킨 다[18].

그간 MBTI를 활용하여 자기수용, 자존감, 타인수용을 향상 시킨 연구는 직장인[19]과 부모의 의사소통에 영향을 미친 연
구[20], 간호대학생의 자기효능감에 관한 연구[21] 등이 있다. 군인을 대상으로는 관심 병사와 일반병사에게 MBTI 프로그 램을 적용하여 자기수용, 자존감, 타인수용을 향상시켜 관계개 선 효과를 보였던 연구[22]가 있었다.

직업군인은 국가의 안보를 책임지고 있어 이들의 정신건강 은 곧 국민의 안전과 직결된다. 이에 본 연구에서는 특수 직역 인 직업군인에게 $\mathrm{MBTI}$ 를 활용한 대인관계향상 프로그램을 적용하여 이들의 자기수용, 자존감 및 타인수용에 미치는 효과 를 검정함으로써 향후 지역사회 정신간호중재의 근거자료로 제공하고자 한다.

\section{2. 연구목적}

본 연구는 MBTI 활용 대인관계향상 프로그램이 직업군인 의 자기수용, 자존감 및 타인수용에 미치는 효과를 규명하기 위한 것으로 구체적인 목적은 다음과 같다.

- MBTI활용 대인관계향상 프로그램이 직업군인의 자기수 용에 미치는 효과를 확인한다.

- MBTI활용 대인관계향상 프로그램이 직업군인의 자존감 에 미치는 효과를 확인한다.

- $\mathrm{MBTI}$ 활용 대인관계향상 프로그램이 직업군인의 타인수 용에 미치는 효과를 확인한다.

\section{3. 연구가설}

- 가설 1. MBTI활용 대인관계향상 프로그램에 참여한 실험 군은 참여하지 않은 대조군보다 자기수용 정도가 높아질 것이다.

- 가설 2. MBTI활용 대인관계향상 프로그램에 참여한 실험 군은 참여하지 않은 대조군보다 자존감 정도가 높아질 것 이다.

- 가설 3. MBTI활용 대인관계향상 프로그램에 참여한 실험 군은 참여하지 않은 대조군보다 타인수용 정도가 높아질 것이다.

\section{연구방법}

\section{1. 연구설계}

본 연구는 MBTI활용 대인관계향상 프로그램이 직업군인 의 자기수용, 자존감 및 타인수용에 미치는 영향을 알아보기 
위하여 실시된 유사실험연구로, 프로그램에 참여한 실험군 과 참여하지 않은 대조군을 둔 비동등성 대조군 사전사후 설 계(Nonequivalent control-group pretest-posttest design) 이다.

\section{2. 연구대상}

본 연구의 대상자는 $\mathrm{G}$ 시 소재의 일개 연대 직업군인으로 현 재 장교와 부사관으로 근무하고 있으며, 부대 내에서 생활하 지 않고 출퇴근을 하는 자에 한하여 본 연구의 취지와 목적에 대한 설명을 듣고 참여에 서면으로 동의한 자이다. 대상자 수 는 $\mathrm{G}^{*}$ Power 3.1을 활용하여 산출하였다. F test, ANCOVA 검 증을 위해 effect size 0.5 , 유의수준 .05 , power .80으로 정하고, numerator $\mathrm{df} 1$, number of groups 2, covariate 3을 투입하 여 연구 표본 크기를 계산한 결과 각 집단에 최소 17 명이 필요 한 것으로 산출되었다. 이를 근거로 탈락률을 고려하여 본 연구 에 참여할 것을 서면으로 동의한 실험군 25 명, 대조군 25 명으 로 프로그램을 시작하였다. 그러나 실험군 중 개인 사정이나 휴가, 업무상의 이유로 불참한 7명이 탈락하였고, 대조군 중 설 문지 응답이 불충분한 7명을 제외함으로써 본 연구에 최종적 으로 참여한 대상자는 실험군 18 명, 대조군 18 명으로 총 36 명 이었다.

\section{3. 연구도구}

\section{1) 자기수용(Self-acceptance)}

자기수용은 자신을 이해하고 있는 그대로 받아들이는 것을 말하며[12] 이를 측정하기 위해서 Phillips [24]의 Self-acceptance 척도를 Son [25]이 번안한 도구를 사용하였다. 총 25개 문 항으로 각 문장은 '언제나 그렇다' 1점에서 '전혀 그렇지 않다' 5점까지인 Likert 5점 척도이며, 전체 점수 범위는 25점에서 125점까지로 점수가 높을수록 자기수용 정도가 높음을 의미한 다. Phillips [24]의 연구에서 신뢰도 Cronbach's $\alpha$ 는 .84였 고, 본 연구에서는 .87이었다.

\section{2) 자존감(Self-esteem)}

자존감은 자신을 수용하고 존중하여 스스로를 가치 있 는 존재라고 느끼는 것을 말하며[13], 이를 측정하기 위해서 Rosenberg [13]의 Self-esteem 척도를 Jeon [26]이 번안한 도 구를 사용하였다. 총 10 개 문항으로 각 문장은 '대체로 그렇지 않다' 1점에서 ‘항상 그렇다' 4점인 Likert 4점 척도이며, 전체
점수 범위는 10 점에서 40 점까지로 점수가 높을수록 자존감 정 도가 높음을 의미한다. Jeon [26]의 연구에서 신뢰도 Cronbach's $\alpha$ 는 .85였고, 본 연구에서는 .79였다.

\section{3) 타인수용(Acceptance of Others)}

타인수용은 상대방을 있는 그대로 받아들이고 긍정적으로 인식하는 것을 말하며[15], 이를 측정하기 위해서 Fey [27]의 Acceptance of Others 척도를 Son [25]이 번안한 도구를 사용 하였다. 총 20개 문항으로 각 문장은 '언제나 그렇다' 1점에서 '전혀 그렇지 않다' 5점까지인 Likert 5점 척도이며, 전체 점수 범위는 20점에서 100점까지로 점수가 높을수록 타인수용 정 도가 높음을 의미한다. 하지만 본 연구에서는 타당도를 저해하 는 5 개를 제외한 15 개의 문항을 사용하였으며, Fey [27]의 연 구에서 신뢰도Cronbach's $\alpha$ 는 .90이었고, 본 연구에서는 .78 이었다. 도구의 타당도 검정을 위해 요인분석 한 결과 KaiserMeyer-Olkin 값은 .628이었고 타인수용은 1 개의 요인으로 구 성되어 있으며, 6 개 문항이 변량의 $68.3 \%$ 를 설명하였다.

\section{4. 실험처치}

주진행자인 본 연구자는 MBTI 강사로 활동하고 있으며, 지 역사회 정신건강복지센터에서 정신전문간호사로 근무하면서 아동·청소년, 직장인 및 자살위기자 등 다양한 대상으로 MBTI 를 활용하여 개인 및 집단상담 프로그램을 진행한 경험을 가지 고 있다.

본 프로그램은 MBTI를 활용한 프로그램 안내서[28]와선행 연구[2,19,22]를 토대로 정신간호학교수, MBTI전문가 1인, 정 신전문간호사 1 인으로부터 내용 타당도 검증을 받아직업군인 에게 적합하게 구성하였다. 이때 4점 Likert 척도(관련 없음 1 점, 문항의 수정 없이는 관련성 판단할 수 없음 2점, 관련 있으 나 약간의 문항 변경 필요 3점, 매우 관련 높음 4 점)를 이용하여 내용타당도지수(Content Validity Index, CVI)를 측정한 결 과 .90 이상으로 나타나 본 프로그램의 내용은 적합한 것으로 나타났다.

프로그램 운영은 총 횟수가 5 9회기, 1회기 시간이 90 120 분 일 때 가장 효과적이라고 밝힌 메타분석 연구[29]를 근거로 대상자의 근무여건을 고려하여 주 1 회, 회기 당 90 분씩, 총 8회 기로 진행하였다. 프로그램 내용은 1회기는 프로그램에 대한 소개와집단의 목적, 일정 및 진행과정을 소개하고 집단의 규칙 을 정하고 사전검사를 실시하였다. 또한 '나의 좌우명은?', '내 인생에서 가장 소중한 것’, ‘나는 어린 시절 꿈을 꾸었다' 등의 
작업을 통해 자신을 진지하게 탐색한 뒤, 참여자들과 공유함으 로써 서로를 이해하고 신뢰를 형성할 수 있도록 하였다. 2회기 는 Kim와 Sim [18]에 의해 한국어판으로 개발된 MBTI 성격유 형검사 도구(Form M)를 사용하여 검사를 실시하고 채점하는 시간을 가졌다. 3 회기는 외향과 내향, 감각과 직관에 대한 설명 과 집단작업을 하여 에너지 방향과 정보를 인식하는 방법에 대 한차이를 알게 하였다. 4 회기는 사고와감정, 판단과 인식에 대 한 설명과 집단작업을 하여 의사결정 유형과 생활양식 태도에 대한 이해를 도왔다. 5 회기는 16 가지 성격유형에 대한 설명을 통해 자신의 잠재력과 긍정성을 알게 하고, 다른 사람과 친해지 기 위한 전략을 세워보고 실제로 적용해 볼 수 있도록 과제를 주었다. 6회기에는 성격유형별 의사소통유형에 대한 이해를 돕고 역할극을 활용하여 효과적인 의사소통 방법 연습하도록 하였고, 7 회기는 군 관련 시청각 자료를 활용하여 성격유형에 따른 차이를 알게 하고 갈등을 해결하는 방법을 배워볼 수 있도 록 하였다. 마지막 회기인 8회기에는 서로에 대한 장점을 공유 하여 긍정적인 피드백을 받을 수 있도록 하였다(Table 1).

\section{5. 자료수집}

본 연구는 B국립병원의 생명윤리심의위원회의 승인(IRB 승인번호: 5-017)을 받았으며, 설문조사에 앞서 G시에 소재한 일개 연대에 연구자가 직접 방문하여 연구의 목적과 취지를 설 명한 후 연대장과 인사관리 담당자에게 장소와 연구진행에 대 한 허락과 동의를 받았다. 자료수집기간은 2015년 6월 2일부터 7월 25일 진행하였으며, 사전에 대상자에게 연구의 목적과 방 법을 설명한 후 원하지 않으면 연구에 참여하지 않아도 됨을 알 려주고 비밀보장을 약속한 후 서면동의서를 받았다. 자료수집 시 후광효과를 차단하기 위해 프로그램 진행자인 연구자를 제 외한 2 인의 연구보조진행자가 실시하였으며, 조사자 간의 측 정오차를 최소화하기 위해 설문조사 실시 전 연구보조진행자 들에게 주는 정보를 통일하고 자료수집방법과 절차 및 교육에 관한 프로토콜을 만들어 연구보조진행자를 교육하였다. 프로 그램은 집단활동의 효과를 높이기 위해 한 그룹 당 12 명과 13 명씩 나누었으며, 12 명은 화요일 오후에, 13 명은 금요일 오후 에 진행하여 주 1 회, 90 분씩 8 주 동안 실시하였다. 실험군과 대 조군 모두 프로그램이 시작하는 6월 2일에 사전 검사를 실시하 였고, 종결하는 7월 25일에 사후 검사를 실시하였다.

실험처치의 확산을 방지하기 위해 같은 연대이지만 업무상 교류가 적고 거리가 떨어진 다른 2 개의 부서를 실험군과 대조 군으로 선정하였다. 자료수집방법의 일관성을 유지하기 위하
여 실험군과 대조군의 사전 설문지는 동일한 시점에 배부하였 고, 사후 설문지도 모두 동일하게 8 주 후의 오후 시간에 수거하 였다. 설문조사 후 실험군과 대조군 모두에게 소정의 답례품 을 제공하였고, 윤리적 고려를 위해 실험군의 프로그램이 종 료 후 대조군 중 희망자에게도 8 회기의 동일한 프로그램을 제 공하였다.

\section{6. 자료분석}

수집된 자료는 SPSS/WIN 25.0 프로그램을 이용하여 분석 하였다. 실험군과 대조군의 일반적 특성은 빈도와 백분율, 평균 과 표준편차로 산출하였다. 종속변수에 대한 집단별 정규분포 를 파악하기 위해 왜도값을 살펴본 결과, 절대값이 1.0 보다 작아 정규분포를 하는 것으로 나타났으며, Kolmogorov-Smirnov 정규성 검정에서 유의수준(p) .05보다 높았고, $\mathrm{Q}-\mathrm{Q}$ 도표에서 데 이터들이 직선에 가까워 정규분포를 이루고 있음을 확인하였 다. 실험군과 대조군의 일반적 특성별 동질성 검정은 한 그룹 의 대상자 수가 5 이하인 경우는 비모수검정인 Fisher's exact probability test로, 5 이상인 경우는 $x^{2}$ test로, 연속변수인 연 령과 근무기간은 평균값을 산출하여 Independent t-test로 분 석하였다. 종속변수에 대한 실험 전 실험군과 대조군의 동질성 검정은 Independent t-test로 분석하였고, 실험처치 후 실험군 과 대조군의 종속변수 차이를 검정하기 위해서 일반적 특성 중 동질성이 검정되지 않은 연령, 결혼유무, 근무기간을 공변인 (covariate)으로 하고 ANCOVA를 실시하였다.

\section{연구결과}

\section{1. 일반적 특성별 동질성 검정}

본 연구의 대상자는 실험군 18 명과 대조군 18 명으로 총 36 명이었다. 전체 대상자의 일반적 특성을 보면 실험군의 평균나 이는 24.5세였으며 대조군은 29.7세였고, 직급은 실험군은 장 교가 $61.1 \%$, 대조군은 부사관이 $61.1 \%$ 로 가장 많았다. 성별은 실험군의 $83.3 \%$, 대조군의 $94.4 \%$ 가 남자였으며, 학력은 대학 교 졸업자가 두 집단 모두 $83.3 \%, 66.7 \%$ 로 가장 많았다. 종교는 '있다'고 응답한 경우가 실험군과 대조군 모두 $66.7 \%$ 로 같았 으며, 결혼유무는 실험군은 미혼이 $88.9 \%$ 로 가장 많았고, 대조 군은 미혼 $55.6 \%$, 기혼이 $33.3 \%$ 였다. 근무기간의 평균은 실험 군은 1.4 년, 대조군은 2.5 년이었고, 근무만족도는 '만족한다'가 실험군 $72.2 \%$, 대조군 $77.8 \%$ 로 가장 많았다. 대상자의 일반적 
Table 1. Contents of an Interpersonal Relationship Improvement Program using MBTI

\begin{tabular}{|c|c|c|c|c|}
\hline Session & Theme & Contents & $\begin{array}{c}\text { Time } \\
\text { (minute) }\end{array}$ & Objective \\
\hline 1 & $\begin{array}{l}\text { Orientation of the } \\
\text { program }\end{array}$ & $\begin{array}{l}\text { - Orientation } \\
\text { - Establishing rule } \\
\text { - Pretest } \\
\text { - Self-introduction }\end{array}$ & 90 & $\begin{array}{l}\text { To establish trust and } \\
\text { intimacy among group } \\
\text { members. }\end{array}$ \\
\hline 2 & Understanding MBTI & $\begin{array}{l}\text { - Understanding about MBTI } \\
\text { - MBTI test }\end{array}$ & 90 & $\begin{array}{l}\text { To increase self- acceptance } \\
\text { \& self-esteem }\end{array}$ \\
\hline 3 & $\begin{array}{l}\text { Understanding the } \\
\text { extroversion- } \\
\text { introversion \& } \\
\text { sensing-intuition }\end{array}$ & $\begin{array}{l}\text { - Explaining the characteristics of } \\
\text { extroversion/introversion } \\
\text { - Group activity } \\
\text {-Features of interpersonal relations } \\
\text {-Feeling envious to others } \\
\text { - Explaining the characteristics of } \\
\text { sensing/intuition } \\
\text { - Group activity } \\
\text { - Thinking that comes into your mind when } \\
\text { you looking at the picture. } \\
\text { - Sharing each other's feeling }\end{array}$ & 90 & \\
\hline 4 & $\begin{array}{l}\text { Understanding the } \\
\text { thinking-feeling \& } \\
\text { judging-perceiving }\end{array}$ & $\begin{array}{l}\text { - Explaining the characteristics of } \\
\text { thinking/feeling } \\
\text { - Group activity } \\
\text { - If your colleague get injured during military } \\
\text { preparation? } \\
\text { - What is a good leader? } \\
\text { - Explaining the characteristics of } \\
\text { judging/ perceiving } \\
\text { - Group activity } \\
\text { - Making travel plans } \\
\text { - Sharing each other's feeling }\end{array}$ & 90 & \\
\hline 5 & $\begin{array}{l}\text { Discovering my } \\
\text { strengths }\end{array}$ & $\begin{array}{l}\text { - Discovering my strength \& other's strength in } \\
\text { accordance with the } 16 \text { personality types } \\
\text { - Training of strategy to get close with others } \\
\text { - Sharing each other's feeling }\end{array}$ & 90 & $\begin{array}{l}\text { To increase self- acceptance } \\
\& \text { self-esteem \& acceptance } \\
\text { of others }\end{array}$ \\
\hline 6 & $\begin{array}{l}\text { Training the effective } \\
\text { communication }\end{array}$ & $\begin{array}{l}\text { - Understanding about communication style of } \\
\text { MBTI } \\
\text { - Role play about the way to improve } \\
\text { communication } \\
\text { - Sharing each other's feeling }\end{array}$ & 90 & $\begin{array}{l}\text { To increase acceptance of } \\
\text { others }\end{array}$ \\
\hline 7 & $\begin{array}{l}\text { Building of } \\
\text { relationships }\end{array}$ & $\begin{array}{l}\text { - Watching video (conflict situation) } \\
\text { - Training of strategies to conflict resolution } \\
\text { - Sharing each other's feeling }\end{array}$ & 90 & \\
\hline 8 & Sharing strengths & $\begin{array}{l}\text { - Sharing each other's strengths } \\
\text { - Sharing each other's feeling } \\
\text { - Posttest }\end{array}$ & 90 & \\
\hline
\end{tabular}

특성에 대한 실험군과 대조군의 사전 동질성 검정을 한 결과, 직급, 성별, 교육정도, 종교, 근무만족도에서는 동질한 것으로 나타났으나 연령, 결혼유무, 근무기간에서 동질하지 않은 것으 로 나타났다(Table 2).

\section{2. 종속변수의 사전 동질성 검정}

$\mathrm{MBTI}$ 활용 대인관계향상 프로그램을 실시하기 전 자기수용 은 실험군의 평균이 $88.83 \pm 11.93$ 점, 대조군 평균은 $90.00 \pm$ 
9.26점으로 두 집단 간에 유의한 차이가 없었고, 자존감은 실험 군의 평균이 $31.94 \pm 4.19$ 점, 대조군의 평균은 30.72 \pm 3.59 점으 로 두 집단 간에 유의한 차이가 없어 두 집단은 동질 한 것으로

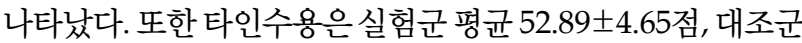
평균 51.61 \pm 6.37 점으로 두 집단 간에 유의한 차이가 없어 두 집단은 동질 한 것으로 나타났다(Table 3).

\section{3. 가설 검정}

1) 가설 1

$\mathrm{MBTI}$ 활용 대인관계향상 프로그램에 참여한 실험군은 참여 하지 않은 대조군보다 자기수용 정도가 높아질 것이다.

$\mathrm{MBTI}$ 활용 대인관계향상 프로그램 실시 후 실험군의 자기 수용 사후 값 평균 $94.00 \pm 12.46$ 점과 대조군 사후 값 평균 89.94 \pm 9.68 점의 차이를 통계적으로 검정하기 위해서 일반적 특성 중 동질성이 검정되지 않은 연령, 결혼유무, 근무기간을 공변인 (covariate)으로 하고 $\mathrm{ANCOVA}$ 를 실시한 결과 유의한 차이가 있었으므로 $(\mathrm{F}=26.39, p<.001)$ 가설 1 은 지지되었다(Table 4).

2) 가설 2

$\mathrm{MBTI}$ 활용 대인관계향상 프로그램에 참여한 실험군은 참여 하지 않은 대조군보다 자존감 정도가 높아질 것이다.

$\mathrm{MBTI}$ 활용 대인관계향상 프로그램 실시 후 실험군의 자존 감 사후 값 평균 $34.06 \pm 3.92$ 점과 대조군 사후 값 평균 $30.89 \pm$ 3.58점의 차이를 통계적으로 검정하기 위해서 일반적 특성 중 동질성이 검정되지 않은 연령, 결혼유무, 근무기간을 공변인 (covariate)으로 하고 ANCOVA를 실시한 결과 유의한 차이가 있었으므로 $(\mathrm{F}=16.61, p<.001)$ 가설 2는 지지되었다(Table 4).

Table 2. Homogeneity Test of General Characteristics

$(N=36)$

\begin{tabular}{|c|c|c|c|c|c|}
\hline \multirow{2}{*}{ Characteristics } & \multirow{2}{*}{ Categories } & \multirow{2}{*}{$\begin{array}{c}\text { Exp. }(\mathrm{n}=18) \\
\mathrm{n}(\%) \text { or } \mathrm{M} \pm \mathrm{SD}\end{array}$} & \multirow{2}{*}{$\begin{array}{c}\text { Cont. }(\mathrm{n}=18) \\
\mathrm{n}(\%) \text { or } \mathrm{M} \pm \mathrm{SD}\end{array}$} & \multirow{2}{*}{$x^{2}$ or $\mathrm{t}$} & \multirow{2}{*}{$p$} \\
\hline & & & & & \\
\hline Age (year) & & $24.5 \pm 2.03$ & $29.7 \pm 6.47$ & -3.23 & .004 \\
\hline Title & $\begin{array}{l}\text { Noncom } \\
\text { Officer }\end{array}$ & $\begin{array}{r}7(38.9) \\
11(61.1)\end{array}$ & $\begin{array}{r}11(61.1) \\
7(38.9)\end{array}$ & 1.78 & .182 \\
\hline Gender & $\begin{array}{l}\text { Male } \\
\text { Female }\end{array}$ & $\begin{array}{r}15(83.3) \\
3(16.7)\end{array}$ & $\begin{array}{c}17(94.4) \\
1(5.6)\end{array}$ & $1.17^{\dagger}$ & .301 \\
\hline Education level & $\begin{array}{l}\text { High school } \\
\text { University } \\
\text { Master }\end{array}$ & $\begin{aligned} 2 & (11.1) \\
15 & (83.3) \\
1 & (5.6)\end{aligned}$ & $\begin{array}{r}2(11.1) \\
12(66.7) \\
4(22.2)\end{array}$ & $2.10^{\dagger}$ & .405 \\
\hline Religion & $\begin{array}{l}\text { Yes } \\
\text { None }\end{array}$ & $\begin{array}{r}12(66.7) \\
6(33.3)\end{array}$ & $\begin{array}{r}12(66.7) \\
6(33.3)\end{array}$ & 0.00 & $>.999$ \\
\hline Marital state & $\begin{array}{l}\text { Single } \\
\text { Married }\end{array}$ & $\begin{array}{r}16(88.9) \\
2(11.1)\end{array}$ & $\begin{array}{r}10(55.6) \\
8(44.4)\end{array}$ & $5.25^{\dagger}$ & .030 \\
\hline Working years & & $1.4 \pm 0.61$ & $2.5 \pm 0.51$ & -5.81 & $<.001$ \\
\hline Job satisfaction & $\begin{array}{l}\text { Low } \\
\text { Moderate } \\
\text { High }\end{array}$ & $\begin{array}{c}1(5.6) \\
4(22.2) \\
13(72.2)\end{array}$ & $\begin{array}{c}0(0.0) \\
4(22.2) \\
14(77.8)\end{array}$ & $1.04^{\dagger}$ & $>.999$ \\
\hline
\end{tabular}

${ }^{\dagger}$ Fisher's exact probability test; Exp.=experimental group; Cont.=control group.

Table 3. Homogeneity Test of Dependent Variables in Pretest

$(N=36)$

\begin{tabular}{|c|c|c|c|c|}
\hline \multirow{2}{*}{ Variables } & Exp. $(n=18)$ & Cont. $(n=18)$ & \multirow{2}{*}{$\mathrm{t}$} & \multirow{2}{*}{$p$} \\
\hline & $\mathrm{M} \pm \mathrm{SD}$ & $\mathrm{M} \pm \mathrm{SD}$ & & \\
\hline Self-acceptance & $88.83 \pm 11.93$ & $90.00 \pm 9.26$ & -0.33 & .745 \\
\hline Self-esteem & $31.94 \pm 4.19$ & $30.72 \pm 3.59$ & 0.94 & .354 \\
\hline Acceptance of others & $52.89 \pm 4.65$ & $51.61 \pm 6.37$ & 0.69 & .497 \\
\hline
\end{tabular}

Exp.=experimental group; Cont. $=$ control group. 
Table 4. Comparison of Dependent Variables between Two Groups in Posttest

\begin{tabular}{|c|c|c|c|c|}
\hline \multirow{2}{*}{ Variables } & Exp. $(n=18)$ & Cont. $(n=18)$ & \multirow{2}{*}{$\mathrm{F}$} & \multirow{2}{*}{$p$} \\
\hline & $\mathrm{M} \pm \mathrm{SD}$ & $\mathrm{M} \pm \mathrm{SD}$ & & \\
\hline Self-acceptance & $94.00 \pm 12.46$ & $89.94 \pm 9.68$ & 26.39 & $<.001$ \\
\hline Self-esteem & $34.06 \pm 3.92$ & $30.89 \pm 3.58$ & 16.61 & $<.001$ \\
\hline Acceptance of others & $54.83 \pm 7.16$ & $51.50 \pm 5.54$ & 0.47 & .017 \\
\hline
\end{tabular}

Exp.=experimental group; Cont.=control group; $\mathrm{F}=$ Analysis of covariance with age, marital status, working years as covariate

\section{3) 가설 3}

$\mathrm{MBTI}$ 활용 대인관계향상 프로그램에 참여한 실험군은 참여 하지 않은 대조군보다 타인수용 정도가 높아질 것이다.

MBTI활용 대인관계향상 프로그램 실시 후 실험군의 타인 수용사후 값 평균 $54.83 \pm 7.16$ 점과 대조군 사후 값 평균 $51.50 \pm$ 5.54 점의 차이를 통계적으로 검정하기 위해서 일반적 특성 중 동질성이 검정되지 않은 연령, 결혼유무, 근무기간을 공변인 (covariate)으로 하고 ANCOVA를 실시한 결과 유의한 차이가 있었으므로 $(\mathrm{F}=0.47, p=.017)$ 가설 3은 지지되었다(Table 4).

\section{논 의}

본 연구는 MBTI활용 대인관계향상 프로그램이 직업군인의 자기수용, 자존감 및 타인수용에 미치는 효과를 검정하고자 실 시되었으며, 연구결과를 논의하면 다음과 같다.

$\mathrm{MBTI}$ 활용 대인관계향상 프로그램에 참여한 실험군이 참여 하지 않은 대조군보다 자기수용 정도가 유의하게 향상되었다. 이 결과는 직업군인을 대상으로 $\mathrm{MBTI}$ 를 활용한 대인관계향 상 프로그램을 실시한 연구가 없어 직접적인 비교는 어렵다. 하지만 MBTI 부모집단 프로그램을 통해 자기수용에 긍정적 인 효과가 있었던 연구결과[20]와 일반병사에게 프로그램을 적용하여 자기수용을 높여 대인관계에 긍정적인 효과가 있었 던 연구결과[22]와 일맥상통한다. 본 연구에서 MBTI를 활용 하여 자신의 성격유형에 대한 객관적 이해를 돕고, '나의 좌우 명', '내 인생에서 가장 소중한 것', '바꾸고 싶은 나의 모습' 작 업을 통해 자신의 내면을 심도 있게 탐색함으로써 자신을 이해 하고 수용 할 수 있게 도운 것으로 생각된다. 실제 프로그램 초 기에는 소극적이거나 무관심한 태도를 보이기도 하고 '전에 MBTI 검사를 해 봤었는데 뭐가 달라질지 잘 모르겠다.', '사람 의 성격을 분류하는 것이 좋은 건지 의문이 든다.' 등의 부정적 인 표현을 하였다. 그러나 프로그램 후에는 '객관적으로 나를 바라보고 깊이 있게 생각할 수 있었던 시간이었다.', '내 유형이 정확히 맞아서 신기했고 유형별로 모였을 때 확실히 구별되어 서 나를 더욱 알아 갈 수 있었다.', '어린 시절에 어떤 꿈을 꾸었
는지, 내 인생에서 가장 소중한 것이 무엇인지를 생각하면서 다 시 한번 나를 돌아보게 된 것 같다.'고 표현하였다. 이는 비진단 검사인 $\mathrm{MBTI}$ 를 활용하여 자신을 객관적으로 관찰하도록 돕 고, 선천적 선호성을 이해함으로써 자신을 수용할 수 있도록 도왔기 때문으로 사료된다.

$\mathrm{MBTI}$ 활용 대인관계향상 프로그램에 참여한 실험군이 참여 하지 않은 대조군보다 자존감 정도가 유의하게 향상되었다. 이 결과는 군인을 대상으로 자존감을 높이기 위해 MBTI를 활용 한 대인관계향상 프로그램을 실시한 연구가 없어 직접적인 비 교는 어렵다. 하지만 직장인을 대상으로 한 MBTI 집단 프로그 램이 자신의 강점과 잠재력을 발견하게 됨으로써 자신에 대한 인식이 긍정적으로 변화되었다는 연구결과[19]와 일치한다. 또한 MBTI 부모집단 프로그램을 통해 자존감에 긍정적인 효 과가 있었던 연구결과[20]와도 일맥상통한다. 본 연구에서는 16 가지 성격유형의 강점탐색, 장점세례식 등의 작업을 통해 자 신의 고유한 강점을 알게 됨으로써 내면에 가지고 있던 열등감 이나 부족감을 해소한 결과로 사료된다. 실제 프로그램 후에 '프로그램에 참여하면서 내가 장점이 많은 사람이라는 것을 깨 닫게 되었다.', '나 뿐만 아니라 동료들의 성격도 이해할 수 있 어서 관계를 더 잘 할 수 있을 것 같은 자신감이 생겼다.' '평소 고민을 나누거나 이야기를 할 수 있는 시간이 적었는데 서로를 깊이 있게 알 수 있었고 긍정적인 말들을 해주어서 고마웠다.' 고 표현하였다. 이는 본 연구 프로그램을 통해 자신의 강점과 잠재력을 발견하고 서로의 감정과 생각을 긍정적으로 전달하 는 과정에서 자존감이 향상된 것으로 보인다.

$\mathrm{MBTI}$ 활용 대인관계향상 프로그램에 참여한 실험군이 참여 하지 않은 대조군보다 타인수용 정도가 유의하게 향상되었다. 이 결과는 직업군인을 대상으로 MBTI를 활용한 대인관계향 상 프로그램을 실시한 연구가 없어 직접적인 비교는 어렵다. 하지만 직장인을 대상으로 한 MBTI 집단 프로그램이 다른 사 람을 인정하고 받아들이게 됨으로써 타인수용에 긍정적인 영 향을 미친 연구[19]와 일치한다. 또한 일반병사를 대상으로 한 연구에서 MBTI 집단상담 프로그램이 다른 사람에 대한 인식 을 변화시키고 효과적인 의사소통 방법을 연습함으로써 타인 
수용을 향상시켰다는 연구결과[22]와도 일맥상통한다. 본 연 구 프로그램에서는 MBTI를 활용하여 다른 사람의 강점을 발 견함으로써 긍정적으로 인식하도록 돕고 '다른 유형과 친해지 기 위한 전략세우기', 'I-massage와 역할극'을 활용한 것이 타 인수용에 도움이 된 것으로 보인다[30]. 실제 프로그램 참여 후 '나와 반대 성향을 가진 사람들이 어떻게 생각하는지 알 수 있 었고 같이 일할 때 도움이 될 것 같다.', '다른 사람의 행동이 틀 린 것이 아니라 다른 것이고 공감을 통한 상호 간의 조화가 필 요함을 느꼈다.'고 표현하였다. 이는 MBTI활용 대인관계향상 프로그램을 통해 인간이 가지고 있는 고유한 성격을 이해하고, 옳고 그름의 판단에서 벗어나 다름의 가치를 인정하도록 도움 으로써 직업군인의 타인수용이 향상된 것으로 사료된다.

본 연구결과를 종합해 볼 때 $\mathrm{MBTI}$ 활용 대인관계향상 프로 그램이 직업군인의 자기수용, 자존감 및 타인수용을 향상시키 는 효과적인 정신간호중재 전략임을 확인할 수 있었다.

본 연구의 제한점은 다음과 같다.

첫째, 본 연구는 일 지역 연대의 직업군인을 대상으로 자기 수용, 자존감 및 타인수용에 미치는 효과를 확인하였으므로 전 국 직업군인을 대상으로 확대 해석하기에는 제한점이 있다. 둘 째, 본 프로그램에 참여한 대상자의 일반적 특성에서 연령, 결 혼유무, 근무기간이 동질하지 않았다. 통계적으로 통제를 하였 으나 후속연구에서는 동질한 집단을 대상으로 효과성을 검정 하여 프로그램에 대한 신뢰성을 확인할 필요성이 있다.

\section{결 론}

본 연구는 MBTI활용 대인관계향상 프로그램이 직업군인의 자기수용과 자존감 및 타인수용에 미치는 효과를 확인하고자 실시하였다. 연구결과 $\mathrm{MBTI}$ 활용 대인관계향상 프로그램은 직업군인의 자기수용, 자존감 및 타인수용을 향상시키는 데 효 과가 있는 간호중재임이 확인되었다. 따라서 향후 직업군인의 대인관계를 향상시키기 위한 중재전략 수립 시 MBTI활용 대 인관계향상 프로그램 연구결과가 유용하게 활용될 수 있을 것 이다.

\section{CONFLICTS OF INTEREST}

The authors declared no conflicts of interest.

\section{ORCID}

Choi, Song Won Kim, Hee Sook https://orcid.org/0000-0002-8644-6294

https://orcid.org/0000-0002-8669-0166

\section{REFERENCES}

1. Seo HS, Kim JE. The effect of self-growth group counseling on adjustment in military of army soldiers. Journal Social Science. 2010;36(3):23-41. https://doi.org/10.15820/khjss.2010.36.3.002

2. Park I, Kim MS, Ko YG. What makes professional officers hard in military Life?: focusing on officers' perception. The Korea Journal of Industrial and Organizational Psychology. 2013;26 (4):625-658. https://doi.org/10.24230/ksiop.26.4.201311.625

3. Segye Times. The suicide rate is twice that of obligation soldiers. Crisis of sergeant. [Internet]. 2013 Dec [cited 2015 Oct 21]. Available from:

http://www.segye.com/content/html/2013/10/21/2013102 1005573.html

4. Kim SI. The influence of job satisfaction, job stress, anger expression, depression, and hopelessness of junior officers of armed forces on suicidal ideation. Korea Journal of Counseling and Psychotherapy. 2014;26(2):545-573.

5. Min J. A study on the characteristics of military forces. Journal of National Defense Studies. 2010;51(3):61-92.

6. Park SI, Lee DG. Influence of job satisfaction, job stress, anger expression, depression, and hopelessness of junior officers of armed forces on their suicidal ideation. Korean Journal of Counseling and Psychotherapy. 2014;26(2):545-573.

7. Kim SA, Kim HL, WOO JH, Park SI, Keum R. Communication abilities, interpersonal relationship, anxiety, and depression in Korean soldiers. Journal of Korean Academy Psychiatric and Mental Health Nursing. 2011;20(1):81-90 https://doi.org/10.12934/jkpmhn.2011.20.1.81

8. Kwun SJ. A study on military junior staff self efficacy and job exhaustion: focused on army sergeants. Journal of Governance Studies. 2011;6(2):199-232.

9. Kim KS, Choi JA. Effect of communication type, stress coping method, and ego-resilience on adjustment to the military service among primary grade executive. Journal of Korea Association of Parent Counseling and Play Therapy. 2013;4:5-18.

10. Park SH, Kim JE, Bang BR. A study on the effects to the communication capability and the accommodation of other person's perspective for the self understanding, the self accommodation and the self communication-centered on the university students in Gungii-do and Seoul. Journal of the Korea Contents Association. 2016;16(7):410-422. https://doi.org/10.5392/jkca.2016.16.07.410

11. Im JO, Jang SS. Trends and suggestions in research on self-acceptance. Journal of Human Understanding and Counseling. 2012;33(1):159-184

12. Song HK. Causal structural analysis among creative personality, achievement goal orientation, self-determination motivation, and self-acceptance for students with cochlear implant. 
National Research Foundation of Korea. 2014;15(4):265-289.

13. Rosenberg M. Society and the adolescent self image. Princeton NJ: Princeton University Press; 1965. 338 p.

14. Park YM, Jo SI. The effect of teacher's satisfactions about the guidance of student teaching on self-esteem and conflict in teaching process of early childhood student teacher. The Korean Association of Regional Development. 2012;12(1):37-56.

15. Kim SHS. The moderating effects of self-acceptance in terms of the interpersonal-relationships, depression, anxiety of high school students. Korea Journal of Child Studies. 2012;33(3): 119-130. https://doi.org/10.5723/kjcs.2012.33.3.119

16. Son HD. Self-up: Self-esteem enhancing group counseling program. The Korea Counselors' Association. 2014;49(49):437-446.

17. Myers IB, Myers PB. Gifts differing: Understanding personality type. 1st ed. Palo alto CA: Consulting Psychologists Press; 1980. 228 p.

18. Kim JT, Sim HS. A study of Korean standardization of MyersBriggs Type Indicator (MBTI). Korea Journal of Counseling and Psychotherapy. 1990;3(1):44-72.

19. Kim HS, Park GR. Effects of an interpersonal relationship improvement program using MBTI: effects on self-esteem, interpersonal relations, and mental health in company employees. Journal of Korean Academy of Psychiatric and Mental Health Nursing. 2010;19(3):261-270. https://doi.org/10.12934/jkpmhn.2010.19.3.261

20. Park KR, Kim HS, Yoon MJ. A parent group counseling program applying MBTI effects of the parenting efficacy and parent-child communication. Journal of Kyungpook Nursing Science. 2018;1(22):63-72.

21. GO MJ. The effect of MBTI growth program for nursing students. Journal of Korean Academy of Psychiatric and Mental
Health Nursing. 2014;23(1):28-37.

https://doi.org/10.12934/jkpmhn.2014.23.1.28

22. Choi HR. MBTI-based group counseling program effect on relationship improvement among military dormitory soldiers - for protective-concerned soldiers and general soldiers. Culture and Convergence. 2019;41(6):309-334.

23. Park SJ. The influence of MBTI personality types on the effect of army outplacement program. [master's thesis]. [Seoul]: Yonsei University; 2009. 96 p.

24. Phillips EL. Attitudes toward self and others: a brief questionnaire report. Journal of Consulting Psychology. 1951;15(1):7981. http://psycnet.apa.org/doi/10.1037/h0054271

25. Son IH. The Effects of small group study on academic achievements, and self acceptance and others acceptance. [master's thesis]. [Busan]: Donga University; 1987. $54 \mathrm{p}$

26. Jeon BJ. Self-esteem: A test of its measurability. Collection of treatises of Yonsei University, 1974;11:107-130.

27. Fey WH. Acceptance by others and its relation to acceptance of self and others: a revaluation. Journal of Abnormal and Social Psychology. 1955;50(2):274-276. https://doi.org/10.1037/h0046876

28. Kim JT, Sim HS. MBTI growth program: workshop leader's guide Korea Institute of Psychological testing: Seoul; 1998. 227 p.

29. Jo MA. A meta-analysis of the effects on counseling groups for the interpersonal relationships. [master's thesis]. [Jeonju]: Chonbuk National University; 2004. 38 p.

30. Kim SH, Park GH. The development of the interpersonal relationship harmony program for university students. Korea Journal of Counseling. 2010;11(1):375-393. https://doi.org/10.15703/kjc.11.1.201003.375 